\title{
Myocardial ischemia during ventilator weaning: a prospective multicenter cohort study
}

\author{
Alexandre Bedet ${ }^{1,2^{*}}$ D, Françoise Tomberli ${ }^{3}$, Gwenael Prat ${ }^{4}$, Pierre Bailly ${ }^{4}$, Achille Kouatchet ${ }^{5}$, Sater Mortaza ${ }^{5}$, \\ Emmanuel Vivier ${ }^{6}$, Sylvene Rosselli, ${ }^{6}$ Larissa Lipskaia ${ }^{1,2}$, Guillaume Carteaux ${ }^{1,2}$, Keyvan Razazi ${ }^{1,2}$ and \\ Armand Mekontso Dessap ${ }^{1,2}$
}

\begin{abstract}
Background: Weaning-induced cardiac pulmonary edema (WiPO) is one of the main mechanisms of weaning failure during mechanical ventilation. We hypothesized that weaning-induced cardiac ischemia ( $\mathrm{WiCl}$ ) may contribute to weaning failure from cardiac origin.

Methods: A prospective cohort study of patients mechanically ventilated for at least $24 \mathrm{~h}$ who failed a first spontaneous breathing trial (SBT) was conducted in four intensive care units. Patients were explored during a second SBT using multiple tools (echocardiography, continuous 12-lead ST monitoring, biomarkers) to scrutinize the mechanisms of weaning failure. WiPO definition was based on three criteria (echocardiographic signs of increased left atrial pressure, increase in B-type natriuretic peptides, or increase in protein concentration during SBT) according to a conservative definition (at least two criteria) and a liberal definition (at least one criterion). WiCl was diagnosed according to the third universal definition of myocardial infarction proposed by the European Society of Cardiology (ESC) and the American Heart Association (AHA) statement for exercise testing.

Results: Among patients who failed a first SBT, WiPO occurred in 124/208 (59.6\%) and 44/208 (21.2\%) patients, according to the liberal and conservative definition, respectively. Among patients with ST monitoring, WiCl was diagnosed in 36/177 (20.3\%) and 12/177 (6.8\%) of them, according to the ESC and AHA definitions, respectively. WiCl was not associated with WiPO and was not associated with weaning outcomes. Only two patients of the cohort were treated for an acute coronary syndrome after the second SBT, and seven other patients required coronary angiography during the weaning period.
\end{abstract}

Conclusions: This observational study showed the common occurrence of pulmonary edema in mechanically ventilated patients who failed a first SBT, but the association with cardiac ischemia and weaning outcomes was weak.

Keywords: Weaning, Cardiac ischemia, Cardiac pulmonary edema, ST monitoring, Echocardiography

\section{Background}

The weaning process represents a critical step for patients admitted in intensive care units and requiring mechanical ventilation. Weaning failure is associated with poor outcomes, and prolonged weaning is associated with increased risk of death [1-3]. Standardized

\footnotetext{
* Correspondence: alexandre.bedet@gmail.com

${ }^{1}$ Medical Intensive Care Unit, DHU A-TVB, Henri Mondor University Hospital,

Assistance Publique - Hôpitaux de Paris, Créteil F-94010, France

${ }^{2}$ Mondor Institute of Biomedical Research, CARMAS Research Group, Paris Est

Créteil University, Créteil F-94010, France

Full list of author information is available at the end of the article
}

weaning protocols with the use of spontaneous breathing trials (SBTs) seem to shorten the duration of mechanical ventilation and could help the clinician to scrutinize the causes of weaning failure [4]. Weaninginduced cardiac pulmonary edema (WiPO), which was described many decades ago [5], is one of the main causes of weaning failure [6]. Recent advances in its diagnosis have been made using new tools such as bedside echocardiography [7] or biomarkers [8-10]. However, the underlying mechanisms of WiPO remain controversial [11]. Weaning-induced cardiac ischemia

(c) The Author(s). 2019 Open Access This article is distributed under the terms of the Creative Commons Attribution 4.0 International License (http://creativecommons.org/licenses/by/4.0/), which permits unrestricted use, distribution, and 
(WiCI) may be a key factor, as weaning from positivepressure ventilation induces some physiologic changes that increase cardiac work and myocardial oxygen demand [12]. However, the relationship between WiCI and weaning outcomes is generally poorly described. This study primarily aimed at exploring $\mathrm{WiCI}$ and WiPO in patients who failed a first SBT. In these patients, cardiac function was assessed using multiple tools (echocardiography, ST monitoring, and cardiac biomarkers) during a second weaning trial. We hypothesized that WiCI may contribute to WiPO, which may influence weaning outcomes.

\section{Methods}

Guidelines for reporting this study were derived from the Strengthening the Reporting of Observational Studies in Epidemiology (STROBE) Statement [13].

\section{Study population}

This prospective multicenter cohort study was performed in four medical or mixed intensive care units of secondary and tertiary hospitals in France from February 2012 to May 2016. Patients screened for enrolment were those intubated for at least $24 \mathrm{~h}$ with ventilator settings allowing to initiate the weaning process $\left[\mathrm{SpO}_{2}>90 \%\right.$ or $\mathrm{PaO}_{2} / \mathrm{FiO}_{2} \geq 150 \mathrm{mmHg}$ with a fraction of inspired oxygen $\left(\mathrm{FiO}_{2}\right) \leq 40 \%$ and a positive end-expiratory pressure (PEEP) $\leq 8 \mathrm{cmH}_{2} \mathrm{O}$ ]. Exclusion criteria included age $<18$ years, decision to withdraw life support, hemodynamic instability with significant doses of vasopressors (dopamine or dobutamine $>10 \mu \mathrm{g} /$ $\mathrm{kg} / \mathrm{min}$, epinephrine or norepinephrine $>0.5 \mathrm{mg} / \mathrm{h}$ ), patient deeply comatose or sedated, and extreme temperatures $\left(<36^{\circ} \mathrm{C}\right.$ or $\left.>39^{\circ} \mathrm{C}\right)$. The modality of the first SBT was either a low-pressure support ventilation without PEEP or a T-piece, as per the recommendations $[14,15]$ and the usual care in the participating units. Criteria for SBT failure were respiratory rate $\geq 35$ breaths/min or increase $\geq 50 \%, \mathrm{SpO}_{2} \leq 90 \%$ or $\mathrm{PaO}_{2} \leq 50 \mathrm{mmHg}$ (with $\mathrm{FiO}_{2} \geq 50 \%$ ), heart rate $\geq 140$ beats/min, new onset of supraventricular or ventricular arrhythmia, systolic arterial pressure $>180$ or $<90 \mathrm{mmHg}$, alteration of consciousness, and diaphoresis or any signs of respiratory distress $[14,15]$. Patients who failed the first SBT were included in the study.

This study was conducted in accordance with the amended Declaration of Helsinki. The protocol was approved by our institution's local ethics committee (Comité de Protection des Personnes Ile-de-France IX, approval number 10-064). The protocol was considered a component of standard care and the patient's consent was waived. Written and oral information about the study was given to patients or families.

\section{Second SBT and weaning outcomes}

No specific therapeutic interventions were recommended to the clinician after the failure of the first SBT. A second SBT, consisting of a 2-h T-piece trial [16], was performed within $24 \mathrm{~h}$ after the first SBT in all included patients. We chose the T-piece trial for the second SBT because this modality may be more prone to stress the cardiorespiratory system in order to diagnose WIPO [6]. Criteria for second SBT failure were the same as for the first SBT. Patients who succeeded the second SBT were extubated. Successful weaning was defined as patient alive and not reintubated within the 7 days following extubation, irrespective of the use of noninvasive ventilation [15]. We classified patients into three groups, according to the WIND classification [1], as follows: short weaning (successful weaning or death within 1 day after the first SBT), difficult weaning (successful weaning or death after more than 1 day but in less than 7 days after the first SBT), and prolonged weaning (successful weaning or death after 7 days following the first SBT).

\section{Definition of WiPO}

Because there is no noninvasive consensual definition of WiPO, we considered three criteria proposed in the recent literature: (i) echocardiographic signs of increased left atrial pressure at the end of the SBT: E/A ratio $>0.95$ and E/e' ratio > 8.5 [17]; (ii) an increase of BNP (absolute change $\geq 48 \mathrm{ng} / \mathrm{l}$ ) or NT-proBNP (absolute change $\geq 21$ $\mathrm{ng} / \mathrm{l}$ ) concentration during the SBT [9]; (iii) an increase of protein concentration (relative change $>6 \%$ ) during the SBT [8]. We further combined these criteria into two definitions of WiPO, as follows: a conservative definition (when at least two criteria were fulfilled) and a liberal definition (when only one criterion was fulfilled).

\section{Echocardiography}

Transthoracic echocardiography was performed by a trained operator just before and at the end of the second SBT, as previously described [18]. Briefly, left ventricular ejection fraction was assessed using Simpson's biplane method or estimated visually when poor spatial resolution did not allow sufficient identification of the endocardium. Wall motion analysis was also visually assessed [19]. In the apical four-chamber view, left atrial pressure were estimated by assessing early (E) and late (A) diastolic wave velocities at the mitral valve using the pulsed-wave Doppler; tissue Doppler early (e') and late (a') wave velocities were also assessed at the lateral mitral valve annulus. Pulsed-wave Doppler of the left ventricular outflow tract was assessed in the apical five-chamber view for cardiac output computation. The existence of significant (at least moderate) mitral regurgitation was assessed using color Doppler [20]. 


\section{Biomarkers}

During second SBT, venous samples were collected to measure plasma levels of brain natriuretic peptide (BNP) or amino terminal pro-brain natriuretic peptide (NTproBNP), protein, and high-sensitive cardiac troponin $\mathrm{T}$ (or troponin I in non-equipped centers) at three time points: before the SBT (in all patients), at the end of SBT (in all patients, whether it was a success or a failure), and $2 \mathrm{~h}$ after the start of SBT (only in patients reconnected prematurely to the ventilator because of SBT failure). We also assessed arterial blood gas analyses before and at the end of SBT.

\section{Definition of WiCl}

ST segment measurements were recorded every minute during the second SBT using a continuous 12-lead electrocardiogram via the monitoring station. We adapted the third universal definition of myocardial infarction proposed by the European Society of Cardiology (ESC) [21] to define electrocardiographic WiCI, as follows: ST elevation in two contiguous leads $(\geq 0.10 \mathrm{mV}$ in all leads other than $\mathrm{V}_{2}-\mathrm{V}_{3} ; \geq 0.20 \mathrm{mV}$ in $\mathrm{V}_{2}-\mathrm{V}_{3}$ in men $\geq 40$ years; $\geq 0.25 \mathrm{mV}$ in $V_{2}-V_{3}$ in men $<40$ years; $\geq 0.15 \mathrm{mV}$ in $\mathrm{V}_{2}-\mathrm{V}_{3}$ in women), or ST depression $\geq 0.05 \mathrm{mV}$ in two contiguous leads. As weaning shares some similarities with a cardiac stress test, another definition was extrapolated from the American Heart Association (AHA) statement for exercise testing as follows: ST elevation or depression $\geq 0.10 \mathrm{mV}$ in two contiguous leads [22].

\section{Statistical analysis}

We hypothesized that the previously reported WiCI prevalences of $6-10 \%$ were probably underestimated given the ancient monitoring techniques used [23, 24]. We estimated that a sample size of 200 patients would allow detecting a prevalence of $\mathrm{WiCI}$ of at least $15 \%$ with an accuracy of 5\% and an alpha risk of 5\% (95\% confidence interval). The data were analyzed using SPSS Base 20 (IBM-SPSS Inc., Chicago, IL, USA). Categorical variables were expressed as numbers [percentage], continuous data with normal distribution as means [standard deviation], and continuous data with non-normal distribution as medians [25th-75th percentiles]. We used the chi-squared or Fisher exact test to compare categorical variables between groups. The Kruskal-Wallis test was used to compare independent data with non-normal distribution and the Mann-Whitney test to compare paired data. Two-sided $p$ values less than 0.05 were considered significant.

\section{Results}

A total of 1749 mechanically ventilated patients were screened for the study. Among these patients, 211 failed a first SBT and 208 were included in the study; ST monitoring was available in 177 of these patients.

\section{Patient population}

Among patients who failed a first SBT, weaning was short in 51/208 [25\%], difficult in 95/208 [46\%], and prolonged in 62/208 patients [30\%] according to the WIND classification. No patients died in the short group while 9/95 patients [9.5\%] and 35/62 patients [56.5\%] died in the difficult and prolonged group, respectively. Patient characteristics were similar in the three groups except for a higher prevalence of heart failure with reduced ejection fraction, septic shock, and ventilator-associated pneumonia before weaning in the prolonged group, as compared to other groups (Additional file 1). Forty-one over 208 [19.7\%] patients had a past history of coronary artery disease, and this prevalence did not differ between the three groups (Additional file 1). The clinical and biological parameters assessed just before the second SBT were also similar between groups, except for longer duration of mechanical ventilation since intubation, higher prevalence of the assist-control ventilation mode and of pulmonary consolidations, more fluid balance since admission, and lower values of MRC score and hemoglobin concentration in patients with poor weaning outcomes as compared to those with short weaning (Table 1). Patients with prolonged weaning had a longer length of stay in ICU and a higher mortality as compared to their counterparts (Additional file 1).

\section{Second SBT}

The median delay between the first and second SBT was 1 day [0-1]. One hundred and thirty-two over 208 patients (63.5\%) failed the second SBT (Table 1). During the second SBT, NT-pro BNP and echocardiographic surrogates of left atrial pressure (E, E/A, and E/e') increased in the failure group, but not in the success group, while an increase in protein concentration was observed in the two groups (Table 2). Only 17 patients had significant mitral regurgitation at the end of the SBT: 14 were mild and 3 were moderate. Overall, WiPO was diagnosed in 124/208 (59.6\%) and 44/208 (21.2\%) patients, according to the liberal and conservative definitions, respectively. WiPO was more frequent in patients who failed the second SBT as compared to successes, and whatever the definition used. WiPO did not influence the overall duration of weaning as assessed by the WIND definition (Table 3). The evolution of other cardiorespiratory parameters during the second SBT is reported in Additional file 2.

ST monitoring could be assessed in 177 patients during the second SBT, and WiCI was diagnosed in 36/177 (20.3\%) and 12/177 (6.8\%) of them, according to the ESC and AHA definitions, respectively. There were more 
Table 1 Clinical and biological data of 208 patients before the second spontaneous breathing trial (SBT)

\begin{tabular}{|c|c|c|c|c|c|}
\hline \multirow[t]{2}{*}{ Clinical and biological data } & \multirow{2}{*}{$\begin{array}{l}\text { All patients } \\
(n=208)\end{array}$} & \multicolumn{3}{|l|}{ Weaning outcome } & \multirow[t]{2}{*}{$p$} \\
\hline & & Short $(n=51)$ & Difficult $(n=95)$ & Prolonged $(n=62)$ & \\
\hline \multicolumn{6}{|l|}{ Clinical data } \\
\hline Body weight, kg & $78(66-95)$ & $81(68-90)$ & $78(66-96)$ & $78(65-92)$ & 0.962 \\
\hline Variation of weight since admission, $\mathrm{kg}$ & $0(-2$ to 4$)$ & $0(-2$ to 4$)$ & $0(-1$ to 3$)$ & $1(-2$ to 5$)$ & 0.965 \\
\hline SOFA score & $3(3-5)$ & $3(2-4)$ & $3(3-5)$ & $4(3-6)$ & 0.130 \\
\hline Richmond Agitation-Sedation Score & $0(0-0)$ & $0(0-0)$ & $0(0-0)$ & $0(0-0)$ & 0.230 \\
\hline Temperature, ${ }^{\circ} \mathrm{C}$ & $37.8(37.5-38.2)$ & $37.8(37.5-38.2)$ & $37.7(37.3-38.2)$ & $37.7(37.4-38.1)$ & 0.745 \\
\hline Fluid balance since admission, $\mathrm{ml}$ & $4500(1677-10,966)$ & $3471(737-6498)$ & 4161 (1052-9654) & $8653(2838-15,121)$ & 0.002 \\
\hline Use of diuretics since admission & $111(53.4)$ & $26(51.0)$ & $48(50.5)$ & $37(59.7)$ & 0.492 \\
\hline Spontaneous cough & $155(76.0)$ & $43(86.0)$ & $69(73.4)$ & $43(71.7)$ & 0.130 \\
\hline Delirium (CAM-ICU) & $70(33.6)$ & $16(31.4)$ & $32(33.7)$ & $22(35.5)$ & 0.915 \\
\hline New or persistent radiological pulmonary consolidation & $58(28.3)$ & $14(28.6)$ & $20(21.1)$ & $24(39.3)$ & 0.047 \\
\hline Duration of mechanical ventilation since intubation & $6(4-13)$ & $6(3-8)$ & $6(3-9)$ & $13(7-20)$ & $<0.001$ \\
\hline Mechanical ventilation & & & & & 0.013 \\
\hline Assist-control ventilation & $35(16.9)$ & $5(9.8)$ & $13(13.8)$ & $17(27.4)$ & \\
\hline Pressure support ventilation & $170(82.1)$ & $46(90.2)$ & $81(86.2)$ & $43(69.4)$ & \\
\hline Others & $2(1.0)$ & $0(0.0)$ & $0(0.0)$ & $2(3.2)$ & \\
\hline Heat and moisture exchanger & $141(68.4)$ & $31(60.8)$ & $65(69.9)$ & $45(72.6)$ & 0.374 \\
\hline Pressure support level, $\mathrm{CmH}_{2} \mathrm{O}$ & $12(10-14)$ & $12(10-13)$ & $12(10-14)$ & $12(10-14)$ & 0.229 \\
\hline PEEP, $\mathrm{cmH}_{2} \mathrm{O}$ & $5(5-6)$ & $5(5-5)$ & $5(5-6)$ & $5(5-5)$ & 0.362 \\
\hline Tidal volume, $\mathrm{ml}$ & $438(376-499)$ & $434(359-479)$ & $443(380-512)$ & $430(378-472)$ & 0.553 \\
\hline Tidal volume per kilogram body weight, mL/kg & $7.1(6.2-8.1)$ & $7.0(6.3-8.3)$ & $7.3(6.3-8.2)$ & $6.7(6.1-7.9)$ & 0.453 \\
\hline Respiratory rate, breaths per minute & $26(20-31)$ & $27(19-32)$ & $25(21-29)$ & $26(20-31)$ & 0.804 \\
\hline Number of tracheal suctions during $24 \mathrm{~h}$ & $7(5-11)$ & $8(6-10)$ & $8(5-12)$ & $6(4-11)$ & 0.424 \\
\hline MRC muscle scale & $50(9-60)$ & $60(40-60)$ & $52(20-60)$ & $25(5-48)$ & 0.002 \\
\hline \multicolumn{6}{|l|}{ Biological data } \\
\hline White blood count, G/l & $11.4(8.3-15.2)$ & $11.1(7.9-13.4)$ & $11.8(8.9-15.1)$ & $12.4(7.8-16.9)$ & 0.460 \\
\hline Creatinine, micromol/l & $78(53-140)$ & $82(58-121)$ & $77(52-142)$ & $75(52-147)$ & 0.761 \\
\hline Protid, $\mathrm{g} / \mathrm{l}$ & $59(54-65)$ & $59(55-66)$ & $57(53-64)$ & $61(55-66)$ & 0.224 \\
\hline Hemoglobin, g/dl & $9.4(8.2-10.8)$ & $9.6(8.3-11.2)$ & $9.6(8.4-10.8)$ & $9.0(7.9-10.1)$ & 0.042 \\
\hline Positive lower respiratory tract sample & 30 & 9 & 10 & 11 & 0.341 \\
\hline Time since intubation, days & $6(4-13)$ & $6(3-8)$ & $6(3-9)$ & $13(7-20)$ & $<0.001$ \\
\hline Type of the second SBT & & & & & 0.455 \\
\hline T-piece & $204(98.1)$ & $51(100.0)$ & $93(97.9)$ & $60(96.8)$ & \\
\hline Pressure support ventilation without PEEP & $4(2.0)$ & $0(0.0)$ & $2(2.1)$ & $2(3.2)$ & \\
\hline Duration of the second SBT, minutes & $60(17-120)$ & $120(55-123)$ & $50(18-120)$ & $24(10-97)$ & $<0.001$ \\
\hline Failure of the second SBT & $132(63.5)$ & $16(31.4)$ & $68(71.6)$ & $48(77.4)$ & $<0.001$ \\
\hline \multicolumn{6}{|l|}{ Reasons for second SBT failure ${ }^{a}$} \\
\hline Respiratory rate $>35 /$ min & $89(65.4)$ & $10(58.8)$ & $43(61.4)$ & $36(73.5)$ & 0.329 \\
\hline $\mathrm{SpO}_{2}<90 \%$ & 47 (34.6) & $6(35.3)$ & $25(35.7)$ & $16(32.7)$ & 0.940 \\
\hline $\mathrm{PCO}_{2}>50 \mathrm{mmHg}$ & $9(6.6)$ & $0(0.0)$ & $8(11.4)$ & $1(2.0)$ & 0.064 \\
\hline Heart rate $>140 / \mathrm{min}$ & $4(2.9)$ & $0(0.0)$ & $2(2.9)$ & $2(4.1)$ & 0.691 \\
\hline Systolic arterial pressure $>180 \mathrm{mmHg}$ & $21(15.4)$ & $2(11.8)$ & $10(14.3)$ & $9(18.4)$ & 0.752 \\
\hline Increased work of breathing or distress & $68(50.0)$ & $8(47.1)$ & $33(47.1)$ & $27(55.1)$ & 0.671 \\
\hline
\end{tabular}


Table 1 Clinical and biological data of 208 patients before the second spontaneous breathing trial (SBT) (Continued)

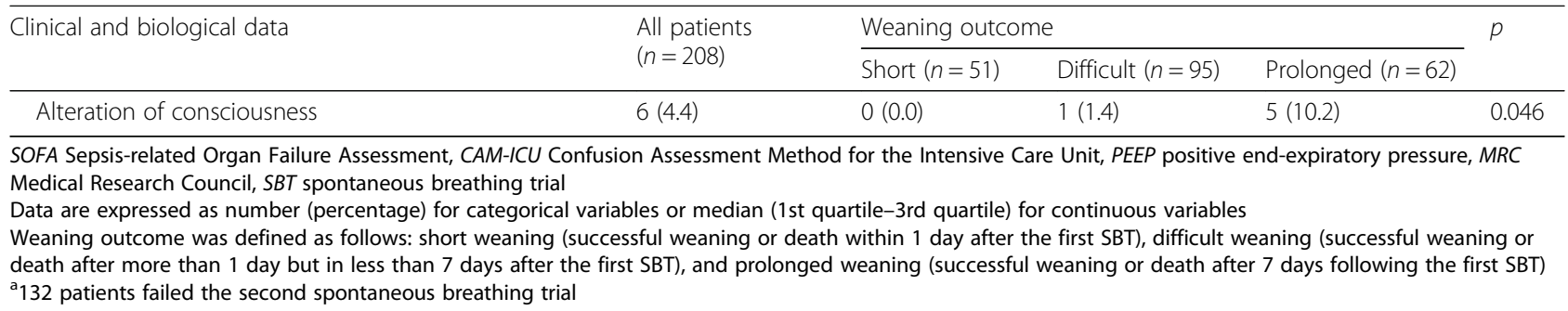

patients admitted for cardiac arrest in the $\mathrm{WiCI}$ group as compared to their counterparts (Additional file 3). Changes in troponin were not different between patients with WiCI and their counterparts (Additional file 4). WiCI was not significantly associated with WiPO (Table 4, Fig. 1), neither with the outcome of the second SBT (Table 3). WiCI was more frequent in the prolonged weaning group when using the AHA, but not ESC definition (Table 3).

\section{Coronary exploration or treatment}

Two patients of the cohort were treated for an acute coronary syndrome after the second SBT, including one patient with a percutaneous reperfusion (the other patient presented a hemorrhagic shock which precluded any reperfusion therapy). Seven patients with a past medical history of coronary artery disease failed their second SBT and were explored with coronary angiography: two patients had coronary lesions without necessity of reperfusion therapy while five patients had no significant coronary lesions (Additional file 5).

\section{Discussion}

We herein report the largest cohort of ventilated patients who were explored for $\mathrm{WiCI}$ and $\mathrm{WiPO}$ during weaning, using multiple noninvasive tools including echocardiography, ST monitoring, and biomarkers. The prevalence of $\mathrm{WiPO}$ and that of $\mathrm{WiCI}$ were not negligible, but their association was weak. In addition, their impact on weaning outcomes was not consistent and depended on the definition and outcome used.

\section{WiPO}

WiPO is one of the main mechanisms of weaning failure [5]. We found a high prevalence of WiPO after a first

Table 2 Dynamic changes of biological and echocardiographic data during the second spontaneous breathing trial

\begin{tabular}{|c|c|c|c|}
\hline Biological and echocardiographic data & Before & At the end & $p$ \\
\hline & \multicolumn{3}{|c|}{ Success $(n=76)$} \\
\hline Troponin T, ng/l & $297(926)$ & $303(969)$ & 0.641 \\
\hline NT-proBNP, ng/l & $4166(7316)$ & $3975(6632)$ & 0.159 \\
\hline Protein, $\mathrm{g} / \mathrm{l}$ & $59.1(10.9)$ & $60.4(10.1)$ & 0.040 \\
\hline E mitral wave, $\mathrm{cm} / \mathrm{s}$ & $87.4(24.4)$ & $89.9(26.7)$ & 0.248 \\
\hline E/A ratio & $0.99(0.39)$ & $1.00(0.52)$ & 0.736 \\
\hline E/e' ratio & $10.6(5.7)$ & $10.7(5.4)$ & 0.778 \\
\hline LVEF, \% & $52(15)$ & $53(14)$ & 0.323 \\
\hline \multirow[t]{2}{*}{$\mathrm{CO}, \mathrm{l} / \mathrm{min}$} & $5.9(1.8)$ & $6.2(2.0)$ & 0.225 \\
\hline & \multicolumn{3}{|c|}{ Failure $(n=132)$} \\
\hline Troponin T, ng/l & $410(1866)$ & $418(1921)$ & 0.326 \\
\hline NT-proBNP, ng/l & $5726(14509)$ & $5983(15476)$ & 0.015 \\
\hline Protein, $g / l$ & $59.8(9.1)$ & $62.0(9.0)$ & $<0.001$ \\
\hline E mitral wave, $\mathrm{cm} / \mathrm{s}$ & $88.6(33.7)$ & $101.9(36.0)$ & $<0.001$ \\
\hline E/A ratio & $1.04(0.54)$ & $1.18(0.61)$ & 0.003 \\
\hline E/e' ratio & $11.1(6.7)$ & $11.8(6.9)$ & 0.040 \\
\hline LVEF, \% & $54(14)$ & $55(15)$ & 0.048 \\
\hline $\mathrm{CO}, \mathrm{l} / \mathrm{min}$ & $5.7(2.0)$ & $6.1(2.2)$ & 0.012 \\
\hline
\end{tabular}

NT-proBNP amino terminal pro-brain natriuretic peptide, $E$ early diastolic wave velocity, $A$ late diastolic wave velocity, $e^{\prime}$ tissue Doppler early wave velocity at the lateral mitral valve annulus, $L V E F$ left ventricle ejection fraction, $C O$ cardiac output

Data are expressed as mean (standard deviation). $p$ values were calculated using paired Student's $t$ test 
Table 3 Prevalence of weaning-induced cardiac pulmonary edema (WiPO) and weaning-induced cardiac ischemia (WiCl) during the second spontaneous breathing trial (SBT)

\begin{tabular}{|c|c|c|c|c|c|c|c|c|}
\hline \multirow[b]{2}{*}{ WiPO } & \multirow{2}{*}{$\begin{array}{l}\text { All patients } \\
(n=208)\end{array}$} & \multicolumn{2}{|c|}{ Second SBT } & \multirow[t]{2}{*}{$p$} & \multicolumn{3}{|c|}{ Weaning outcome } & \multirow[t]{2}{*}{$p$} \\
\hline & & $\begin{array}{l}\text { Success } \\
(n=76)\end{array}$ & $\begin{array}{l}\text { Failure } \\
(n=132)\end{array}$ & & $\begin{array}{l}\text { Simple } \\
(n=51)\end{array}$ & $\begin{array}{l}\text { Difficult } \\
(n=95)\end{array}$ & $\begin{array}{l}\text { Prolonged } \\
(n=62)\end{array}$ & \\
\hline Liberal definition & $124(59.6)$ & $35(46.1)$ & $89(67.4)$ & 0.002 & $30(58.8)$ & $54(56.8)$ & $40(64.5)$ & 0.626 \\
\hline Conservative definition & $44(21.2)$ & $9(11.8)$ & $35(26.5)$ & 0.013 & $8(15.7)$ & $22(23.2)$ & $14(22.6)$ & 0.524 \\
\hline \multirow[b]{2}{*}{$\mathrm{WiCl}$} & \multirow{2}{*}{$\begin{array}{l}\text { All patients } \\
(n=177)\end{array}$} & \multicolumn{2}{|c|}{ Second SBT } & $p$ & \multicolumn{3}{|c|}{ Weaning outcome } & $p$ \\
\hline & & $\begin{array}{l}\text { Success } \\
(n=64)\end{array}$ & $\begin{array}{l}\text { Failure } \\
(n=113)\end{array}$ & & $\begin{array}{l}\text { Simple } \\
(n=43)\end{array}$ & $\begin{array}{l}\text { Difficult } \\
(n=83)\end{array}$ & $\begin{array}{l}\text { Prolonged } \\
(n=51)\end{array}$ & \\
\hline ESC 2012 & $36(20.3)$ & $13(20.3)$ & $23(20.4)$ & 0.995 & $8(18.6)$ & $15(18.1)$ & $13(25.5)$ & 0.555 \\
\hline AHA 2013 & $12(6.8)$ & $3(4.7)$ & $9(8.0)$ & 0.540 & $0(0.0)$ & $5(6.0)$ & $7(13.7)$ & 0.029 \\
\hline
\end{tabular}

SBT spontaneous breathing trial, WiPO weaning-induced cardiac pulmonary edema, WiCl weaning-induced cardiac ischemia, ESC European Society of Cardiology, AHA American Heart Association

Data are expressed as number of patients (percentage)

WiPO was defined as follows: conservative definition (at least two positive criteria) and liberal definition (at least one positive criterion). Criteria used for WiPO were as follows: (i) echocardiographic findings at the end of the SBT: E/A ratio $>0.95$ and E/e' ratio $>8.5$; (ii) increase of BNP ( $\geq 48$ ng/l) or NT-proBNP ( $\geq 21$ ng/l) levels during the SBT; (iii) increase of protein level ( $>6 \%$ ) during the SBT. WiCl was defined as follows: (i) ESC 2012: ST elevation in two contiguous leads ( $\geq 0.10$ $\mathrm{mV}$ in all leads other than $\mathrm{V}_{2}-\mathrm{V}_{3} ; \geq 0.20 \mathrm{mV}$ in $\mathrm{V}_{2}-\mathrm{V}_{3}$ in men $\geq 40$ years; $\geq 0.25 \mathrm{mV}$ in $\mathrm{V}_{2}-\mathrm{V}_{3}$ in men $<40$ years; $\geq 0.15 \mathrm{mV}$ in $\mathrm{V}_{2}-\mathrm{V}_{3}$ in women), or $\mathrm{ST}$ depression $\geq$ $0.05 \mathrm{mV}$ in two contiguous leads; (ii) AHA 2013: ST elevation or depression $\geq 0.10 \mathrm{mV}$ in two contiguous leads

Weaning outcome was defined as follows: short weaning (successful weaning or death within 1 day after the first SBT), difficult weaning (successful weaning or death after more than 1 day but in less than 7 days after the first SBT), and prolonged weaning (successful weaning or death after 7 days following the first SBT)

SBT failure. This result is consistent with previous studies $[8,17,25,26]$. The gold standard to evaluate LV filling pressures is to measure the pulmonary artery occlusion pressure using a pulmonary artery catheter. Because our patients were not equipped with such device, we chose to combine three noninvasive criteria as proposed by the recent literature, namely echocardiography [17], cardiac biomarkers [9], and protidemia [8]. We observed significant dynamic changes in these surrogates of left atrial pressure during SBT failure, and the prevalence of WiPO in our study (21 to 60\%) is in accordance with that found with the gold standard pulmonary artery catheter (44\%) [17].

Overall, WiPO was more frequent in patients who failed the second SBT as compared to successes, whatever the definition used (conservative or liberal). However, nearly half of the patients who succeeded the second SBT had at least one criterion for WiPO. This result is consistent with previous reports suggesting a significant increase in left atrial pressure during SBT, even in the case of success [27].

The lack of association between WiPO and weaning outcomes in our series may be explained by an early depletive management prompted by the initial evolution and the first SBT failure. In fact, more than half of patients received diuretics before the second SBT. Patient selection may also be important. Only one quarter of our patients had a short weaning (with a successful extubation less than $24 \mathrm{~h}$ after the first $\mathrm{SBT}$ ), a proportion lower than that reported in the WIND study (57\%). This discrepancy is at least in part explained by the fact that we included only patients who failed their first SBT. The incidence of WIPO in our study could be overestimated due to the increased proportion of unsuccessful SBT after a first SBT failure. The median delay between the first and the second SBT was very short in our study with a median of 1 day. These patients were successfully extubated on

Table 4 Prevalence of weaning-induced cardiac pulmonary edema (WiPO) in patients with weaning-induced cardiac ischemia (WiCl) during the second spontaneous breathing trial

\begin{tabular}{|c|c|c|c|c|c|c|}
\hline \multirow[t]{2}{*}{$\mathrm{WiCl}$} & \multicolumn{2}{|c|}{ WiPO (liberal definition) } & \multirow[t]{2}{*}{$p$} & \multicolumn{2}{|c|}{ WiPO (conservative definition) } & \multirow[t]{2}{*}{$p$} \\
\hline & No $(n=73)$ & Yes $(n=104)$ & & No $(n=141)$ & Yes $(n=36)$ & \\
\hline ESC 2012 & $11(15.1)$ & $25(24.0)$ & 0.144 & $26(18.4)$ & $10(27.8)$ & 0.214 \\
\hline AHA 2013 & $6(8.2)$ & $6(5.8)$ & 0.555 & $11(7.8)$ & $1(2.8)$ & 0.464 \\
\hline
\end{tabular}

WiPO weaning-induced cardiac pulmonary edema, WiCl weaning-induced cardiac ischemia, ESC European Society of Cardiology, AHA American Heart Association Data are expressed as number of patients (percentage)

WiPO was defined as follows: conservative definition (at least two positive criteria) and liberal definition (at least one positive criterion). Criteria used for WiPO were as follows: (i) echocardiographic findings at the end of the SBT: E/A ratio $>0.95$ and E/e' ratio $>8.5$; (ii) increase of BNP ( $\geq 48$ ng/l) or NT-proBNP ( $\geq 21$ ng/l) levels during the SBT; (iii) increase of protein level ( $>6 \%$ ) during the SBT. WiCl was defined as follows: (i) ESC 2012: ST elevation in two contiguous leads ( $\geq 0.10$ $\mathrm{mV}$ in all leads other than $\mathrm{V}_{2}-\mathrm{V}_{3} ; \geq 0.20 \mathrm{mV}$ in $\mathrm{V}_{2}-\mathrm{V}_{3}$ in men $\geq 40$ years; $\geq 0.25 \mathrm{mV}$ in $\mathrm{V}_{2}-\mathrm{V}_{3}$ in men $<40$ years; $\geq 0.15 \mathrm{mV}$ in $\mathrm{V}_{2}-\mathrm{V}_{3}$ in women), or $\mathrm{ST}$ depression $\geq$ $0.05 \mathrm{mV}$ in two contiguous leads; (ii) AHA 2013: ST elevation or depression $\geq 0.10 \mathrm{mV}$ in two contiguous leads 


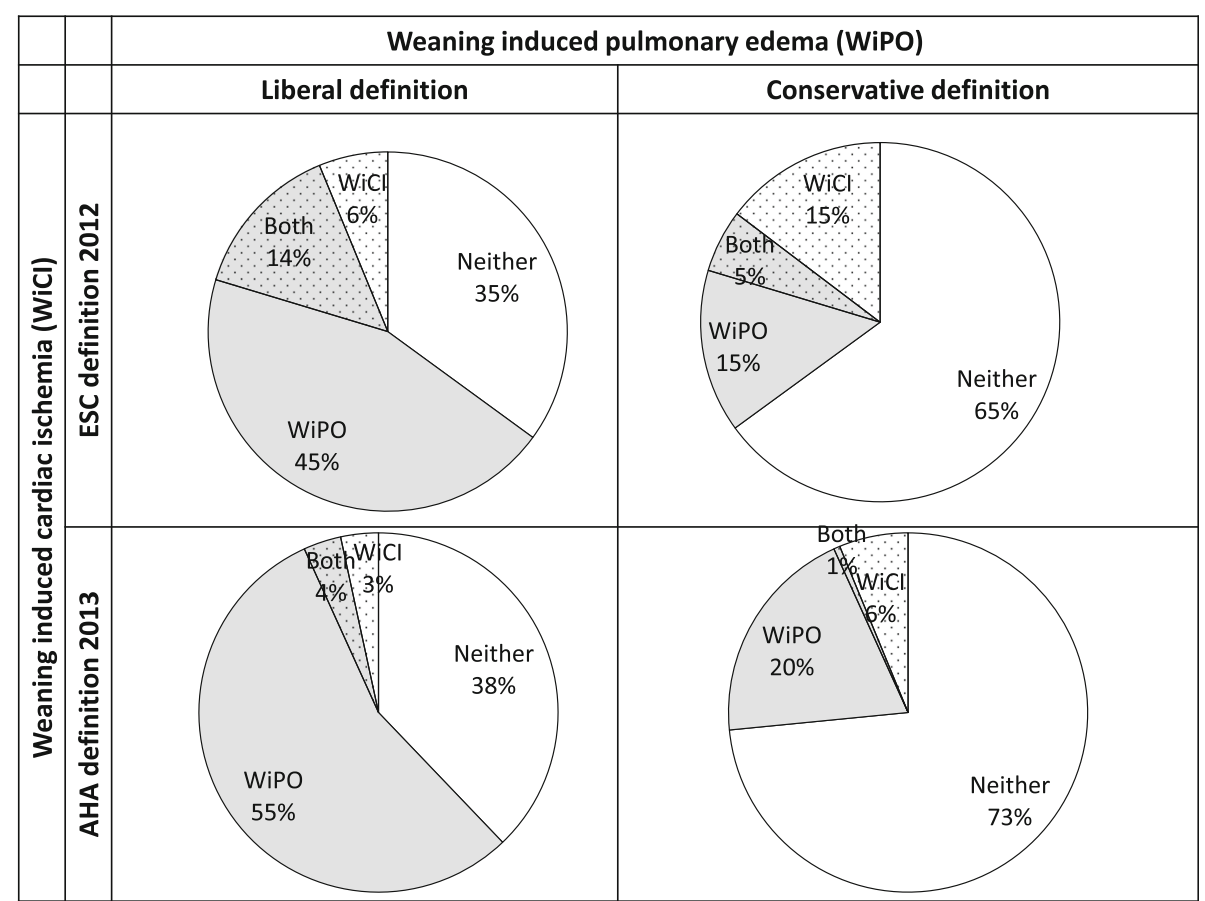

Fig. 1 Pie charts of the prevalence of weaning-induced cardiac pulmonary edema (WiPO, according to conservative or liberal definition) and weaning-induced cardiac ischemia ( $\mathrm{WiCl}$, according to European Society of Cardiology-ESC-2012 or American Heart Association-AHA-2013 definition) in mechanically ventilated patients during the second spontaneous breathing trial

the next day (within $24 \mathrm{~h}$ after the first and the second SBT).

\section{WiCl}

Prevalence of WiCI during the second SBT was less pronounced, as compared to WiPO, and varied between $6.8 \%$ and $20.3 \%$, depending on the definition used. During weaning, silent myocardial ischemia was reported in high-risk postoperative patients [28] and in patients with a known coronary artery disease [23]. Prevalence of $\mathrm{WiCI}$ in the general population of critically ill patients varied between 0 and $70 \%$ across small cohorts [11, 24, 29], but the method of diagnosis and definitions often differed from ours. The association between $\mathrm{WiCI}$ and weaning outcome was weak in our study and only significant for the most restrictive definition derived from AHA statement for exercise testing. Electrocardiographic changes may not be specific to diagnose myocardial ischemia and may reflect myocardial injury whatever its cause [30]. However, ECG monitoring during cardiac stress is recommended as a first-line test to diagnose stable coronary artery disease and to detect transient myocardial ischemia [22, 31]. The association between $\mathrm{WiCI}$ and $\mathrm{WiPO}$ was also weak, suggesting that non-ischemic mechanisms may instead contribute to WiPO. In fact, the role of diastolic dysfunction seems central in the pathophysiology of WiPO [18]. The removal of positive-pressure support during weaning increases left ventricular preload and afterload and may impair left ventricular compliance [32, 33]. The ability of left ventricle to improve diastolic performance and maintain normal filling pressures during stress may be of paramount importance during weaning. Future strategies should aim at differentiating non-ischemic myocardial injury from myocardial infarction [30]. Biomarkers of cardiac injury (troponin) seemed of little help to detect transient myocardial ischemia during weaning in our study. Only three patients had significant variations in troponin I during weaning, and none of these patients experienced electrocardiographic changes. Further studies should assess the usefulness of other biomarkers with a shorter half-life time (e.g., myoglobin) in this setting.

\section{Therapeutic implications}

Only two patients with significant modifications of ST monitoring were treated for an acute coronary syndrome after the second SBT. Although quite infrequent, aggressive therapeutic interventions (such as coronary reperfusion) may sometimes be required to successfully extubate those patients $[34,35]$. The preexistence of a known coronary artery disease (before admission to ICU) was not associated with WiCI. Whether undiagnosed coronary artery disease could be associated with WiCI remains unknown. Future studies should explore strategies aimed at detecting patients 
with clinically relevant cardiac ischemia during the weaning process.

\section{Strengths and limitations}

Out study is the first to explore myocardial ischemia in a large cohort of patients who failed a first SBT. Strengths of our study include its prospective and multicentric design and the comprehensive assessment of cardiac function with multiple tools (echocardiography, continuous 12-lead ECG ST measurement, cardiac biomarkers). Limitations include the non-blinded and observational nature of the study, the absence of invasive monitoring which precluded any direct measurement of left atrial pressure, and the need to use multiple indirect criteria to define WiPO, owing to the lack of consensus in the literature. We did not assess lung ultrasonography because studies suggesting a role for this technique for the assessment of WIPO [36] were published after we started our study. In addition, the generalizability of our findings is limited by the fact that we examined a sub-sample of patients who had failed an initial SBT. Last, mitral regurgitation assessment was not exhaustive in our study and mainly used color Doppler, which may have led to quantification errors.

\section{Conclusions}

WiPO occurred in a significant number of critically ill patients who failed a first SBT, while WiCI was less frequent. The correlation between $\mathrm{WiPO}$ and $\mathrm{WiCI}$ was weak, and their association with weaning outcomes was weak in this non-blinded observational series.

\section{Supplementary information}

Supplementary information accompanies this paper at https://doi.org/10. 1186/s13054-019-2601-8.

Additional file 1. Characteristics and outcomes of 208 patients during weaning. (PDF $113 \mathrm{~kb}$ )

Additional file 2. Clinical and biological variables during the second spontaneous breathing trial (SBT). (PDF $145 \mathrm{~kb}$ )

Additional file 3. Characteristics and outcomes of 208 patients who failed a first spontaneous breathing trial (SBT), according to the prevalence of weaning-induced cardiac ischemia (WiCl). (PDF 147 kb)

Additional file 4. Changes in biological variables during the second spontaneous breathing trial (SBT), according to the prevalence of weaning-induced cardiac ischemia (WiCl). (PDF $131 \mathrm{~kb}$ )

Additional file 5. Characteristics of nine patients with coronary invasive exploration or treatment during weaning. (PDF $135 \mathrm{~kb}$ )

\section{Abbreviations}

A: Late diastolic mitral wave velocity; a': Tissue Doppler late diastolic wave velocity at the lateral mitral valve annulus; AHA: American Heart Association; BNP: Brain natriuretic peptide; E: Early diastolic mitral wave velocity; e': Tissue Doppler early diastolic wave velocity at the lateral mitral valve annulus; ESC: European Society of Cardiology; $\mathrm{FiO}_{2}$ : Fraction of inspired oxygen; NTproBNP: Amino terminal pro-brain natriuretic peptide; PEEP: Positive end- expiratory pressure; SBT: Spontaneous breathing trial; WiPO: Weaninginduced pulmonary edema; WiCl: Weaning-induced cardiac ischemia

\section{Acknowledgements \\ Not applicable.}

\section{Promotion}

Assistance Publique-Hôpitaux de Paris (Délégation Régionale à la Recherche Clinique et à I'Innovation, Unité de Recherche Clinique Henri Mondor).

\section{Authors' contributions}

$A B$ takes responsibility for (is the guarantor of) the content of the manuscript, including the data and analysis. AB had full access to all of the data in the study and takes responsibility for the integrity of the data and the accuracy of the data analysis, including and especially any adverse effects. FT, GP, PB, AK, SM, EV, SR, LL, GC, KR, and AMD contributed substantially to the study design, data analysis and interpretation, and the writing of the manuscript. All authors read and approved the final manuscript.

\section{Funding}

French Ministry of Health (DGOS, Programme Hospitalier de Recherche Clinique National 2005: AOM05104).

\section{Availability of data and materials}

The datasets used and/or analyzed during the current study are available from the corresponding author on reasonable request.

\section{Ethics approval and consent to participate}

This study was conducted in accordance with the amended Declaration of Helsinki. The protocol was approved by our institution's local ethics committee (Comité de Protection des Personnes Ile-de-France IX, approval number 10-064). The protocol was considered a component of standard care and the patient's consent was waived. Written and oral information about the study was given to patients or families.

Consent for publication

Not applicable.

\section{Competing interests}

The authors declare that they have no competing interests.

\section{Author details}

${ }^{1}$ Medical Intensive Care Unit, DHU A-TVB, Henri Mondor University Hospital, Assistance Publique - Hôpitaux de Paris, Créteil F-94010, France. ${ }^{2}$ Mondor Institute of Biomedical Research, CARMAS Research Group, Paris Est Créteil University, Créteil F-94010, France. ${ }^{3}$ Surgical Intensive Care Unit, DHU A-TVB, Henri Mondor University Hospital, Assistance Publique - Hôpitaux de Paris, Créteil F-94010, France. ${ }^{4}$ Intensive Care Unit, Cavale Blanche, Brest Regional University Hospital, 29200 Brest, France. ${ }^{5}$ Medical Intensive Care Unit, Angers University Hospital, 49933 Angers, France. ${ }^{6}$ Intensive Care Unit, Saint-Joseph Saint-Luc Hospital, 69007 Lyon, France.

Received: 12 June 2019 Accepted: 6 September 2019

Published online: 18 September 2019

References

1. Béduneau G, Pham T, Schortgen F, Piquilloud L, Zogheib E, Jonas M, et al. Epidemiology of weaning outcome according to a new definition. The WIND study. Am J Respir Crit Care Med. 2016;195:772-83.

2. Peñuelas O, Frutos-Vivar F, Fernández C, Anzueto A, Epstein SK, Apezteguía C, et al. Characteristics and outcomes of ventilated patients according to time to liberation from mechanical ventilation. Am J Respir Crit Care Med. 2011:184:430-7.

3. Sellares J, Ferrer M, Cano E, Loureiro H, Valencia M, Torres A. Predictors of prolonged weaning and survival during ventilator weaning in a respiratory ICU. Intensive Care Med. 2011;37:775-84.

4. Blackwood B, Alderdice F, Burns K, Cardwell C, Lavery G, O'Halloran P. Use of weaning protocols for reducing duration of mechanical ventilation in critically ill adult patients: Cochrane systematic review and meta-analysis. BMJ. 2011;342:c7237. 
5. Lemaire F, Teboul J-L, Cinotti L, Giotto G, Abrouk F, Steg G, et al. Acute left ventricular dysfunction during unsuccessful weaning from mechanical ventilation. J Am Soc Anesthesiol. 1988;69:171-9.

6. Cabello B, Thille AW, Roche-Campo F, Brochard L, Gómez FJ, Mancebo J. Physiological comparison of three spontaneous breathing trials in difficultto-wean patients. Intensive Care Med. 2010;36:1171-9.

7. Caille V, Amiel J-B, Charron C, Belliard G, Vieillard-Baron A, Vignon P. Echocardiography: a help in the weaning process. Crit Care. 2010;14:R120.

8. Anguel N, Monnet X, Osman D, Castelain V, Richard C, Teboul J-L. Increase in plasma protein concentration for diagnosing weaning-induced pulmonary oedema. Intensive Care Med. 2008;34:1231.

9. Zapata L, Vera P, Roglan A, Gich I, Ordonez-Llanos J, Betbesé AJ. B-type natriuretic peptides for prediction and diagnosis of weaning failure from cardiac origin. Intensive Care Med. 2011;37:477-85.

10. Grasso S, Leone A, De Michele M, Anaclerio R, Cafarelli A, Ancona G, et al. Use of N-terminal pro-brain natriuretic peptide to detect acute cardiac dysfunction during weaning failure in difficult-to-wean patients with chronic obstructive pulmonary disease *. Crit Care Med. 2007;35:96-105.

11. Richard C, Teboul J-L, Archambaud F, Hebert J-L, Michaut P, Auzepy P. Left ventricular function during weaning of patients with chronic obstructive pulmonary disease. Intensive Care Med. 1994;20:181-6.

12. Lamia B, Monnet $X$, Teboul JL. Weaning-induced cardiac dysfunction. In: Vincent J-L, editor. Yearb Intensive Care Emerg Med 2005. New York: Springer; 2005. p. 239-45.

13. von Elm E, Altman DG, Egger M, Pocock SJ, Gøtzsche PC, Vandenbroucke JP. Strengthening the reporting of observational studies in epidemiology (STROBE) statement: guidelines for reporting observational studies. BMJ. 2007:335:806-8.

14. Boles J-M, Bion J, Connors A, Herridge M, Marsh B, Melot C, et al. Weaning from mechanical ventilation. Eur Respir J. 2007:29:1033-56.

15. Quintard H, I'Her E, Pottecher J, Adnet F, Constantin J-M, De Jong A, et al. Experts' guidelines of intubation and extubation of the ICU patient of French Society of Anaesthesia and Intensive Care Medicine (SFAR) and French-speaking Intensive Care Society (SRLF). Ann Intensive Care. 2019;9:13.

16. Vallverdú I, Calaf N, Subirana M, Net A, Benito S, Mancebo J. Clinical characteristics, respiratory functional parameters, and outcome of a twohour T-piece trial in patients weaning from mechanical ventilation. Am J Respir Crit Care Med. 1998;158:1855-62.

17. Lamia B, Maizel J, Ochagavia A, Chemla D, Osman D, Richard C, et al. Echocardiographic diagnosis of pulmonary artery occlusion pressure elevation during weaning from mechanical ventilation*. Crit Care Med. 2009;37:1696-701.

18. Roche-Campo F, Bedet A, Vivier E, Brochard L, Mekontso DA. Cardiac function during weaning failure: the role of diastolic dysfunction. Ann Intensive Care. 2018;8:2.

19. Lang RM, Badano LP, Mor-Avi V, Afilalo J, Armstrong A, Ernande L, et al. Recommendations for cardiac chamber quantification by echocardiography in adults: an update from the American Society of Echocardiography and the European Association of Cardiovascular Imaging. J Am Soc Echocardiogr Off Publ Am Soc Echocardiogr. 2015;28:1-39.e14.

20. Zoghbi WA, Adams D, Bonow RO, Enriquez-Sarano M, Foster E, Grayburn PA, et al. Recommendations for noninvasive evaluation of native valvular regurgitation: a report from the American Society of Echocardiography developed in collaboration with the Society for Cardiovascular Magnetic Resonance. J Am Soc Echocardiogr. 2017;30:303-71.

21. Thygesen K, Alpert JS, Jaffe AS, Simoons ML, Chaitman BR, White HD. Third universal definition of myocardial infarction. Circulation. 2012;126:2020-35.

22. Fletcher GF, Ades PA, Kligfield P, Arena R, Balady GJ, Bittner VA, et al. Exercise standards for testing and training: a scientific statement from the American Heart Association. Circulation. 2013;128:873-934.

23. Srivastava S, Chatila W, Amoateng-adjepong Y, Kanagasegar S, Jacob B, Zarich $\mathrm{S}$, et al. Myocardial ischemia and weaning failure in patients with coronary artery disease: an update. Crit Care Med. 1999;27:2109-12.

24. Chatila W, Ani S, Guaglianone D, Jacob B, Amoateng-Adjepong Y, Manthous CA. Cardiac ischemia during weaning from mechanical ventilation. Chest. 1996:109:1577-83

25. Jubran A, Mathru M, Dries D, Tobin MJ. Continuous recordings of mixed venous oxygen saturation during weaning from mechanical ventilation and the ramifications thereof. Am J Respir Crit Care Med. 1998;158:1763-9.
26. Paulus S, Lehot JJ, Bastien O, Piriou V, George M, Estanove S. Enoximone and acute left ventricular failure during weaning from mechanical ventilation after cardiac surgery. Crit Care Med. 1994;22:74-80.

27. Liu J, Shen F, Teboul J-L, Anguel N, Beurton A, Bezaz N, et al. Cardiac dysfunction induced by weaning from mechanical ventilation: incidence, risk factors, and effects of fluid removal. Crit Care. 2016;20:369.

28. Abalos A, Leibowitz AB, Distefano D, Halpern N, Iberti TJ. Myocardial ischemia during the weaning period. Am J Crit Care. 1992;1:32-6.

29. Frazier SK, Brom H, Widener J, Pender L, Stone KS, Moser DK. Prevalence of myocardial ischemia during mechanical ventilation and weaning and its effects on weaning success. Heart Lung J Acute Crit Care. 2006;35:363-73.

30. Thygesen K, Alpert JS, Jaffe AS, Chaitman BR, Bax JJ, Morrow DA, et al. Fourth universal definition of myocardial infarction (2018). Circulation. 2018; 138:e618-51.

31. Task Force Members, Montalescot G, Sechtem U, Achenbach S, Andreotti F, Arden C, et al. 2013 ESC guidelines on the management of stable coronary artery disease: the Task Force on the management of stable coronary artery disease of the European Society of Cardiology. Eur Heart J. 2013;34:2949-3003.

32. Papanikolaou J, Makris D, Saranteas T, Karakitsos D, Zintzaras E, Karabinis A, et al. New insights into weaning from mechanical ventilation: left ventricular diastolic dysfunction is a key player. Intensive Care Med. 2011;37: 1976-85.

33. Konomi I, Tasoulis A, Kaltsi I, Karatzanos E, Vasileiadis I, Temperikidis P, et al. Left ventricular diastolic dysfunction--an independent risk factor for weaning failure from mechanical ventilation. Anaesth Intensive Care. 2016; 44:466-73.

34. Demoule A, Lefort $Y$, Lopes $M-E$, Lemaire F. Successful weaning from mechanical ventilation after coronary angioplasty. Br J Anaesth. 2004;93: 295-7.

35. Carrié C, Bui HN, Gerbaud E, Vargas F, Hilbert G. Myocardial ischaemia and weaning failure: is angioplasty the heart of the problem? Intensive Care Med. 2011:37:1223-4.

36. Ferré A, Guillot M, Lichtenstein D, Mezière G, Richard C, Teboul J-L, et al. Lung ultrasound allows the diagnosis of weaning-induced pulmonary oedema. Intensive Care Med. 2019;45:601-8

\section{Publisher's Note}

Springer Nature remains neutral with regard to jurisdictional claims in published maps and institutional affiliations.
Ready to submit your research? Choose BMC and benefit from:

- fast, convenient online submission

- thorough peer review by experienced researchers in your field

- rapid publication on acceptance

- support for research data, including large and complex data types

- gold Open Access which fosters wider collaboration and increased citations

- maximum visibility for your research: over $100 \mathrm{M}$ website views per year

At $\mathrm{BMC}$, research is always in progress.

Learn more biomedcentral.com/submissions 